\title{
Retraction Note to: Meta-analysis of the relationship between single nucleotide polymorphism rs72689236 of caspase-3 and Kawasaki disease
}

\author{
Yanlin Xing $^{1} \cdot$ Hong Wang ${ }^{1}$ Xiaomei Liu ${ }^{2} \cdot$ Xianyi Yu ${ }^{1} \cdot$ Rui Chen $^{1} \cdot$ \\ Ce Wang ${ }^{1} \cdot$ Xuexin $\mathrm{Yu}^{1} \cdot$ Le Sun ${ }^{1}$
}

Published online: 18 August 2015

(C) Springer Science+Business Media Dordrecht 2015

Retraction Note to: Mol Biol Rep (2014) 41:6377-6381
DOI 10.1007/s11033-014-3517-7

The Publisher and Editor retract this article in accordance with the recommendations of the Committee on Publica tion Ethics (COPE). After a thorough investigation we have strong reason to believe that the peer review process was compromised.

The online version of the original article can be found under doi:10.1007/s11033-014-3517-7.

Xianyi Yu

xianyiyu1688@hotmail.com

1 Department of Pediatrics, Shengjing Hospital of China Medical University, No. 36 Sanhao Street, Heping District, Shenyang 110004, Liaoning, China

2 Experimental research center, Shengjing Hospital of China Medical University, Shenyang 110004, China 